\title{
Effects of Thermal Creep of Prestressing Steel on Post-tensioned Concrete Slabs in and after Fire
}

\author{
Y. Wei and F. T. K. Au* \\ Department of Civil Engineering, The University of Hong Kong, Hong Kong, China.
}

Abstract: The effects of thermal creep of prestressing steel on post-tensioned concrete slabs in and after fire were investigated based on existing thermal creep model and calibrated parameters in this paper. A nonlinear finite element model was built up employing ABAQUS package, taking into account frictionless contact behaviour between prestressing steel tendons and surrounding concrete. The nonlinear material behaviour of concrete and prestressing steel at elevated temperatures was taken into account, where three material models for prestressing steel were adopted with or without considering thermal creep, and based on the model from EN 1992-1-2. The finite element model developed was verified against experimental results from the literature, showing that the model considering thermal creep was more accurate. Then the fire resistance period and responses of post-tensioned concrete slabs in and after fire were investigated based on the verified model. Ignoring thermal creep underestimated the fire resistance period but overestimated the residual tendon stresses. The model from EN 1992-1-2 achieved nearly the same effects as the model considering thermal creep in fire but might yield inaccurate evaluation of

* Corresponding author: Professor F. T. K. Au;

E-mail: francis.au@hku.hk;

Tel: (852) 2859-2650; Fax: (852) 2559-5337;

Address: Department of Civil Engineering, The University of Hong Kong, Pokfulam Road, Hong Kong, China. 
residual tendon stresses. The model considering thermal creep worked well under fire and in the post-fire conditions yielding reasonable predictions.

Keywords: fire, post-tensioned concrete slab, prestressing steel, thermal creep

\section{Introduction}

Post-tensioned (PT) concrete slabs have been widely used in building structures with the advantages of large span and light weight, which is achieved by suitable layout of prestressing tendons in the slabs, in parabolic, draped or straight profile. The tendons with proper profiles can provide equivalent balancing loads to counteract external loads on a slab, thereby enhancing its load-carrying capacity. When PT concrete slabs are exposed to fire, the tendon forces will be greatly reduced at elevated temperatures, with simultaneous degradation of mechanical properties, thermal elongation and more importantly thermal creep of prestressing steel tendons, which will affect their fire resistance periods and post-fire responses. In particular, the thermal creep of prestressing tendons at elevated temperatures (e.g. above $300^{\circ} \mathrm{C}$ ) is irrecoverable, but its effects on PT concrete slabs have not been thoroughly investigated, even though research results on PT slabs in fire have been presented by others [1].

A series of fire tests on PT concrete slabs have been conducted over the past decade mainly in China and the UK, investigating their fire resistance periods and failure modes for 
improvement of fire resistance performance. Gao et al. [2] carried out fire tests of three-span unbonded PT concrete continuous slabs with the end span under fire, and found lateral bending cracks and longitudinal cracks appearing at the top surface of slabs along prestressing tendons and the recorded tendon forces to increase briefly and then decrease significantly. Yuan et al. [3] further investigated the behaviour and failure modes of three-span unbonded PT concrete continuous slabs, and observed the main failure modes to be formation of plastic hinges near the middle support and rupture of prestressing strands. Zheng et al. [4] conducted a series of tests of unbonded PT concrete slabs in fire, focusing on concrete spalling and variations of forces in the prestressing strands. Bailey and Ellobody [5] conducted a series of fire tests of simply-supported unbonded PT concrete slabs under standard fire condition (ISO 834). The failure mechanisms of the slabs were investigated and the strains of the prestressing steel strands were recorded. Some strands even ruptured in the tests, so the temperatures of the strands were controlled around $400^{\circ} \mathrm{C}$ to avoid the rupturing again. In these tests, it was observed that the forces of prestressing strands varied or the strands ruptured, but the behaviour of the strands was not yet clearly understood.

This issue has drawn attention from other researchers [6,7]. To investigate the behaviour of the prestressing steel strands under high stresses at elevated temperatures, tests were conducted by MacLean [6], but without considering the interaction with concrete. Local heating-soaking-cooling regime was applied to strands to investigate the stress variation in 
the whole process, and the permanent stress loss after elevated temperatures. Gales [7] further conducted another series of tests of strands with parabolic profile and practical lengths accounting for multi-span continuous PT floors, still adopting the local heating-soaking-cooling regime but with a smaller heated length ratio. The tests indicated that the strands with smaller heated length ratio were prone to rupture. While these tests have enhanced our understanding of prestresssing steel strands under high stresses at elevated temperatures, more should be done to take into account the interaction with concrete and various effects on the fire resistance period and post-fire responses of PT concrete slabs.

In this study, the effects were investigated by finite element analysis (FEA) based on an existing thermal creep model [8] and the available calibrated parameters [9]. A nonlinear finite element (FE) model was built up by the ABAQUS package using 3-D solid elements for concrete and tendons, and 3-D truss elements for the steel bars, taking into account the frictionless contact between prestressing tendons and surrounding concrete, and the nonlinear material properties of concrete and prestressing steel at elevated temperatures. The three material models for prestressing steel included models with and without considering thermal creep, and the model from EN 1992-1-2 [10] with implicit consideration of thermal creep. The FE model was verified against available experimental results $[5,11]$. The fire resistance periods of PT concrete slabs under standard fire condition and responses of PT concrete slabs in parametric fires taken from EN 1991-1-2 [12] were 
investigated based on the verified FE model, considering various material models for prestressing steel.

\section{Existing thermal creep model}

Thermal creep is an important factor in the fire resistance analysis and design of PT concrete slabs. Three stages can be observed in the creep process as shown in Fig. 1(a). The first stage develops rapidly but at decreasing strain rate, being called the primary creep; the second stage develops linearly at the minimum strain rate that remains nearly constant, being called the secondary creep; and the third stage is characterized by accelerating strain rate until rupture, being called the tertiary creep [13]. Secondary creep is of great concern at elevated temperatures. The secondary creep rate obeys Arrhenius’s Law as

$$
\frac{\partial \varepsilon_{c r}}{\partial t} \propto \exp \left(-\frac{Q_{c}}{R T}\right) \quad \frac{d \sigma}{d t}=0
$$

where $\varepsilon_{c r}$ is the creep strain; $t$ is time; $Q_{c}$ is the activation energy for thermal creep, which is roughly the activation energy for lattice self-diffusion when it is above half of the melting temperature (in Kelvin); $R$ is the gas constant; $T$ is the temperature in Kelvin; and $\sigma$ is the creep strain. According to Dorn's creep theory as presented by Harmathy [8], the temperature-compensated time $\theta$ is defined as

$$
\theta=\int_{0}^{t} \exp \left(-\frac{Q_{c}}{R T}\right) d t
$$

Differentiating Eq. 2 with respect to time $t$, and substituting into Eq. 1 give

$$
\frac{\partial \varepsilon_{c r}}{\partial \theta}=\frac{\partial \varepsilon_{c r}}{\partial t} \exp \left(\frac{Q_{c}}{R T}\right) \equiv Z
$$

where $Z$ is the Zener-Hollomon parameter, that is taken as a function of stress and 
independent of temperature as shown in Fig. 1(b). The dimensionless parameter $\varepsilon_{c r, 0}$ in Fig. 1(b) is obtained by extending the straight line for secondary creep to the $\varepsilon_{c r}$ axis, and is uniquely determined by stress but independent of temperature as well.

Identifications of parameters $Q_{c}, Z$ and $\varepsilon_{c r, 0}$ are essential. Harmathy and Stanzak [14] have presented equations for the parameters by testing prestressing steel to ASTM A421 (Grade 1725) at the maximum stress of 690MPa, which have been shown to be inappropriate for stresses up to 1000MPa [15]. Recently, Gales et al. [9] presented a new set of equations for the parameters based on tests of prestressing steel to ASTM A416 (Grade 1860), where $Q_{c}$ is taken as $\frac{Q_{c}}{R}=30556$ [14], and $Z$ and $\varepsilon_{c r, 0}$ are given by

$$
\begin{array}{ll}
\mathrm{Z}=2.7 \times 10^{13} e^{0.012 \sigma} & \text { for } 690<\sigma<1000 \mathrm{MPa} \\
\varepsilon_{c r, 0}=1.13 \times 10^{-7} \sigma^{1.63} & \text { for } 690<\sigma<1000 \mathrm{MPa}
\end{array}
$$

which have been calibrated properly. A model have been proposed by Harmathy [8] to describe the thermal creep strain with the aid of parameters of $Z$ and $\varepsilon_{c r, 0}$, taking into account primary creep, is given by

$$
\varepsilon^{c r}=\frac{\varepsilon_{c r, 0}}{\ln 2} \cosh ^{-1}\left(2^{Z \theta / \varepsilon_{c r, 0}}\right) \quad \frac{d \sigma}{d t}=0
$$

This model is adopted here using the calibrated parameters of Gales et al. [9] to describe the thermal creep strain of prestressing steel in PT concrete slabs.

\section{Numerical modelling}

\subsection{Finite element model}


The FE model is developed based on the specimens of PT concrete slabs $[5,11]$ tested by Bailey and Ellobody, with depth of $160 \mathrm{~mm}$, width of $1600 \mathrm{~mm}$, overall length of $4300 \mathrm{~mm}$ and clear span of $4000 \mathrm{~mm}$. There are three parabolic tendons at $530 \mathrm{~mm}$ spacing symmetrically arranged in each slab with a nominal diameter of $15.7 \mathrm{~mm}$ and cross sectional area of $150 \mathrm{~mm}^{2}$. At mid-span, the distance from the soffit of slab to the centre of tendon is $42 \mathrm{~mm}$. Bursting reinforcement is provided to resist tensile bursting forces around individual anchorages, but no passive reinforcement is provided at the bottom of the slab to resist bending moments.

The FE model was built up using the package ABAQUS, using 3-D solid elements for concrete and tendons, and 3-D truss elements for the steel bars. By symmetry, only one-quarter of the slab was modelled with a total of 8550 elements for concrete and 186 elements for tendons as shown in Fig. 2, which has been proved to be sufficient to predict the thermal and structural performance of the slab. Since each prestressing tendon is unbonded to the surrounding concrete, frictionless contact between them has been incorporated in the model. Bursting reinforcement has been embedded in the slab assuming no slip between the steel bars and surrounding concrete.

\subsection{Material model}

The damaged plasticity model of ABAQUS was used to account for the nonlinear behaviour of concrete in tension and compression. At elevated temperatures, the uniaxial 
compressive strength of concrete is denoted as $f_{c \theta}$, which is obtained by applying reduction factors prescribed in EN 1992-1-2 [10] to the strength $f_{c}$ at ambient condition, where $f_{c}$ is cylinder strength taken to be 0.8 times the cube strength according to EN 1992-1-1 [16]. The uniaxial tensile strength $f_{t \theta}$, at elevated temperature is taken as $0.1 f_{c \theta}$. The stress-strain responses at ambient condition under uniaxial compression are assumed to comply with the concrete model of EN 1992-1-1 [16] as shown in Fig. 3. The stress-strain responses at elevated temperatures as shown in Fig. 4 are assumed to comply with the concrete model of EN 1992-1-2 [10], which is specifically used for structural fire-resistance analysis and implicitly incorporates load-induced transient thermal strain. The stress-strain curves shown in Figs. 3(a) and 4(a) are assumed to respond linearly before reaching the stresses of $0.4 f_{c}$ and $0.4 f_{c \theta}$ respectively, while nonlinear responses are assumed beyond such values until reaching the ultimate strength. At the post-peak stage of descending branch, nonlinear response is assumed in the model shown in Fig. 3(a), but linear response is assumed in the model shown in Fig. 4(a) for convenience of numerical convergence at elevated temperatures.

Under uniaxial tension condition, the stress-strain response is assumed to be linear before reaching the peak tensile strength, after which cracks propagate across some section. At ambient condition, bilinear softening stress-crack opening displacement relationship based on concrete fracture energy is used to account for concrete cracking behaviour as shown in Fig. 3(b) [17]. At elevated temperatures, it is assumed that the fracture energy is the same 
as that at ambient condition, but bilinear softening stress-crack displacement responses that change with tensile strength are assumed as shown in Fig. 4(b). The fracture energy is obtained based on an empirical formula proposed by Bazant [17], namely

$$
G_{F}=2.5 \alpha_{0}\left(\frac{f_{c}}{0.051}\right)^{0.46}\left(1+\frac{d_{a}}{11.27}\right)^{0.22}\left(\frac{w}{c}\right)^{-0.30}
$$

where $\alpha_{0}$ accounts for aggregate types: $\alpha_{0}=1$ for rounded aggregate, and $\alpha_{0}=1.44$ for crushed or angular aggregate; $f_{c}$ is the compressive strength of concrete; $d_{a}$ is the maximum diameter of aggregate; and $w / c$ denotes the water to cement ratio.

The prestressing steel strands have a measured elastic modulus of 227GPa, yield strength of 1710MPa and ultimate strength of 1867MP at ambient condition [11]. At elevated temperatures, the mechanical properties are reduced according to the reduction factors prescribed in EN 1992-1-2 [10]. The stress-strain responses of prestressing steel strands are described by three models, including the model in EN 1992-1-2 [10] denoted as "Eurocode 2” as shown in Fig. 5(a), the basic model accounting for elastic-plastic linear hardening denoted as "model without creep" as shown in Fig. 5(b), and the basic model with thermal creep denoted as "model with creep". For the basic model, the moduli of elasticity at elevated temperature and during cooling process can be obtained by the equation proposed by MacLean [6], namely

$$
\frac{E_{T}}{E_{20}}=-2 \times 10^{-6} T^{2}+0.2 \times 10^{-6} T+0.987
$$

where $E_{T}$ denotes the modulus of elasticity at elevated temperature and during cooling process; and $E_{20}$ denotes the modulus of elasticity at ambient temperature. The residual 
yield strength and ultimate strength after heating can be obtained from the empirical equations proposed by Hertz [18] by the reduction factor

$$
\bar{k}=\varphi+\frac{1-\varphi}{1+\left(\frac{T}{T_{1}}\right)+\left(\frac{T}{T_{2}}\right)^{2}+\left(\frac{T}{T_{8}}\right)^{8}+\left(\frac{T}{T_{64}}\right)^{64}}
$$

where is the reduction factor for yield strength and ultimate strength after heating; $T$ is the maximum temperature reached during heating in degree Celsius; and $\left(\varphi, T_{1}, T_{2}, T_{8}, T_{64}\right)=$ $(0.2,100000,750,550)$.

\subsection{Procedures of analysis}

FEA was conducted by a sequentially coupled thermal-stress analysis procedure using ABAQUS, in which heat transfer analysis was first carried out to obtain temperature field that was applied as thermal loading to the FE model for structural analysis.

The FE model for heat transfer analysis was established using 3-D solid elements (DC3D8) for concrete and tendons, and link elements (DC1D2) for bursting reinforcement. The thermal conductivity and specific heat of concrete and prestressing steel are taken from EN 1992-1-2 [10] and EN 1993-1-2 [19]. The moisture content of concrete was taken into account by adjusting the specific heat at temperature of $115^{\circ} \mathrm{C}$. According to EN 1991-1-2 [12], a constant convection factor of $25 \mathrm{~W} / \mathrm{m}^{2} \mathrm{~K}$ and a constant emissivity of 0.8 were set for the fire-exposed surface, while $9 \mathrm{~W} / \mathrm{m}^{2} \mathrm{~K}$ was set for the fire-unexposed surface. The gap 
thermal conductivity at the contact between prestressing steel strands and the surrounding concrete was assumed to be $200 \mathrm{~W} / \mathrm{m}^{2} \mathrm{~K}$.

The FE model for structural analysis was established using 3-D solid elements (C3D8R) for concrete and tendons, and truss elements (T3D2) for bursting reinforcement. The prestressing of tendons was modelled by initial stresses. A loading of $156.6 \mathrm{kN}$ including the self-weight and live load was applied on the FE model according to the test conditions. Thermal loading was applied by predefined field in ABAQUS. In addition, a linear coefficient of thermal expansion of $8.1 \times 10^{-6} /{ }^{\circ} \mathrm{C}$ was used for concrete with limestone aggregate and $13.2 \times 10^{-6} /{ }^{\circ} \mathrm{C}$ for concrete with Thames gravel aggregate. In accordance with EN 1992-1-2 [10], the thermal elongation of prestressing steel with reference to the length at $20^{\circ} \mathrm{C}$ was taken as

$$
\varepsilon_{T}(T)=-2.016 \times 10^{-4}+10^{-5} T+0.4 \times 10^{-8} T^{2} \quad 20^{\circ} \mathrm{C} \leq T \leq 1200^{\circ} \mathrm{C}
$$

where $\varepsilon_{T}$ is thermal expansion strain at temperature $T\left({ }^{\circ} \mathrm{C}\right)$.

\section{Results and validations of FE model}

The FE model is verified at ambient condition and in fire by comparing the results with available test results. The four tests taken to verify the FE model are denoted as T1, T2, T3 and $\mathrm{T} 5$ respectively in accordance with the identification of simply-supported specimens by Bailey and Ellobody [5]. The properties of concrete for the tests [5] are shown in Table 1. 


\subsection{Results and validation of FE model at ambient condition}

Tests T1 and T2 were conducted by Ellobody and Bailey [11] to investigate the behaviour of unbonded PT concrete slabs at ambient condition, based on which an FE model was developed. Slab $\mathrm{T} 1$ was loaded to $106.7 \mathrm{kN}$ with a central deflection of $5.5 \mathrm{~mm}$ and then unloaded to $41.7 \mathrm{kN}$, and again loaded to failure with concrete crushing, from which an ultimate failure load of $156.7 \mathrm{kN}$ with a central deflection of $81.9 \mathrm{~mm}$ was obtained. Slab T2 was loaded to failure with concrete crushing and tendon yielding, from which an ultimate failure load of $178.2 \mathrm{kN}$ with a central deflection of $93.5 \mathrm{~mm}$ was obtained. Table 1 shows that specimens $\mathrm{T} 1$ and $\mathrm{T} 2$ have concrete cube strengths of $44.4 \mathrm{MPa}$ and $48.2 \mathrm{MPa}$, respectively, which has caused the different failure modes and ultimate loads [11].

Comparison of the FE and test results is shown in Fig. 6. Fig. 6(a) shows that the load-deflection curve from FEA agrees well with that of test T1 up to a load of $156 \mathrm{kN}$ with a central deflection of $60.6 \mathrm{~mm}$. Under a load of $106.7 \mathrm{kN}$, the central deflection of $5.1 \mathrm{~mm}$ from FEA is slightly below the $5.5 \mathrm{~mm}$ from test. However, FEA has predicted an ultimate load of $177.6 \mathrm{kN}$ at a central deflection of $117 \mathrm{~mm}$ with tendon yielding, which is $13.3 \%$ above the ultimate load obtained from test T1. Fig. 6(b) shows that the load-deflection curve from FEA agrees very well with that of test T2. The ultimate load from FEA is $178.7 \mathrm{kN}$ with a central deflection of $101 \mathrm{~mm}$ and tendon yielding, which is quite close to those of test T2. Besides, as observed in the comparison of the load-strain curve of 
prestressing tendon from FEA with those of Test T2 in Fig. 6(c), the trend agrees well with those of individual tendons in the test, in which LT, MT and RT indicate the left, middle and right tendons, respectively, and SG1, SG2 and SG3 denote their corresponding strain gauges. The strain from FEA remains nearly constant up to $132.5 \mathrm{kN}$, which slightly exceeds the $130.9 \mathrm{kN}$ from test.

\subsection{Results and validation of FE model in fire}

Fire tests were conducted by Bailey and Ellobody [5] to investigate fire resistance and responses of unbonded PT concrete slabs in fire, two of which without longitudinal restraints were denoted as T3 and T5. Table 1 shows that specimens T3 and T5 have different concrete cube strengths and aggregate types with different thermal expansion coefficients. The slabs were mounted on top of a furnace with a span of $3.2 \mathrm{~m}$ and exposed to fire. The thermocouples distributed at the top of furnace and $350 \mathrm{~mm}$ below the slab recorded the average furnace temperature. The thermocouples embedded in the concrete slabs were used to measure the temperatures of "hot surface" (bottom surface of slab exposed to fire), "cold surface” (top surface of slab exposed to ambient condition), "tendon” and "mid-surface" (mid-height of slab).

An interesting phenomenon observed in the fire tests is the appearance of longitudinal cracks on the unexposed surface along the tendons throughout the tests [5]. Cracks were observed at 20min and 18min in tests $\mathrm{T} 3$ and T5, respectively, after initiating fire [5]. 
Similar phenomena were also observed in the fire tests on unbonded PT concrete slabs conducted by Gao et al. [2] and Yuan et al. [3]. From the FEA of T3 using the model with creep, it is found that the tensile plastic strains above tendons (Fig. 7) increase gradually with time, which agrees well with the observed longitudinal cracks in tests. Besides, in the analysis by Ellobody and Bailey [20], the distribution of tensile stresses in transverse direction was used to indicate the cracking, but their variation with time was not presented. The variations of transverse stresses of selected elements above the central tendon in Fig. 8 undergo four stages. At the first stage, the elements are under very small compressive stresses, which are caused by transverse bending of the slab under loads. At the second stage, the compressive stresses increase dramatically, which is caused by transverse bending induced by lateral soffit thermal expansion with rapid rise of soffit temperature. At the third stage, the stresses change rapidly from compression to tension, as a result of increasing deformation. At the fourth stage, when the tensile stresses reach the tensile strength of concrete, cracking occurs and the tensile stresses drop rapidly. Obviously the longitudinal cross-section of the slab is weaker at the tendon positions because of the splitting. The occurrence of cracking at about 20min as predicted by FEA agrees well with the experimental observation. It also verifies the relationship between longitudinal cracking and deformations caused by lateral thermal expansion.

Comparison of the temperatures and deflections from FEA with the test results of T3 in Fig. 9 shows good agreement between them. Fig. 9(a) shows that the hot surface temperature of 
FEA agrees well with that of the test, but the tendon temperature of FEA is slightly below that of the test after about 100min. Besides, the mid-surface temperature of FEA also agrees well with that of the test, but the cold surface temperature of FEA is obviously below that of the test until the end of session, which may be caused by water vaporization, dehydration and mass transfer that are not modelled in FEA. The deflection curves from FEA with three models of prestresing steel shown in Fig. 9(b) all agree well with that from the test under the measured furnace temperatures, in which the deflection from Eurocode 2 is slightly higher, but those from models with and without creep are slightly lower, compared with that from the test. Besides, the deflection from the model with creep is slightly higher than that from the model without creep and much closer to the test result. Tendon yielding is predicted by the model without creep to occur at approximately $85 \mathrm{~min}$ with tendon temperature at about $310^{\circ} \mathrm{C}$, which gives a very conservative estimate of fire resistance period of unbonded PT concrete slabs.

Comparison of deflection and tendon stress from FEA with the test results of T5 in Fig. 10 shows good agreement for deflection but some discrepancies for tendon stresses. Fig. 10(a) shows that the deflections predicted by the three models all agree well with that from test, where the deflection predicted by Eurocode 2 is slight above that from test, and those predicted by models with and without creep are nearly the same and slightly below that from the test. Both the model with and without creep predict tendon yielding to occur at nearly the same time with tendon temperature at about $225^{\circ} \mathrm{C}$, which gives a very 
conservative estimate of fire resistance period. Fig. 10(b) shows that the tendon stresses predicted by the three models rise for about 20min and then drop. In particular, the stress predicted by Eurocode 2 deviates most from the rest in its descending branch. The stresses predicted by the model with and without creep are closer to that of the test, but after tendon yielding, they begin to deviate more from that of the test. This suggests that the thermal creep of prestressing steel has been underestimated, causing the tendons to yield early.

In conclusion, the FE model has been verified to be effective and robust. The results predicted by Eurocode 2 are conservative with slightly higher deflection and much lower tendon stress. The results predicted by the model without creep are also conservative with respect to early tendon yielding. The results predicted by the model with creep are much better compared with the test results, except that the thermal creep strain is underestimated at relatively lower temperatures. The findings indicate that the model of Eurocode 2 for prestressing tendon which accounts for thermal creep implicitly performs well in fire condition, the model without creep gives conservative estimate of fire resistance period and the model with creep gives more accurate results.

\section{Fire resistance period of slabs in standard fire}

The fire resistance period of slabs in standard fire (ISO 834) is unknown as the furnace could not follow the standard fire strictly and tests were stopped in advance to avoid collapse. The fire resistance period of unbonded PT concrete slabs is investigated here 
based on the verified FE model for T3. The criteria for judgment of fire resistance include fracture of prestressing tendon and significant increase of deflection rate.

From the responses of slab under standard fire condition obtained from the verified FE model as shown in Fig. 11, the central deflection of slab and stress of prestressing tendon increase rapidly with the dramatic rise of temperature in first few minutes, together with steep temperature gradient across the slab section, causing flexural curvature and thermal expansion. Afterwards, with the rise of temperature becoming slower, the temperature gradient tends to be gentle, leading to slow increase of deflection. Besides, the degradation of mechanical properties of concrete and prestressing tendons with the rise of temperature also contributes to the slab deflection. Under the standard fire condition, the deflection continues to increase and the mechanical properties degrade until the slab collapses, which is reflected by fracture of prestressing tendon or significant increase of deflection rate.

Fig. 11(a) shows that Eurocode 2 predicts higher deflection than the other models. The deflections predicted by models with and without creep are nearly the same up to $90 \mathrm{~min}$, after which the former increases further and deviates from the latter, while the latter stops at $116 \mathrm{~min}$ for tendon rupture at the tendon temperature of about $430^{\circ} \mathrm{C}$. Moreover, the model without creep predicts early tendon yielding at $70 \mathrm{~min}$. The deflections predicted by Eurocode 2 and the model with creep tend to increase rapidly after 120 min, which suggest at least a fire resistance period of 120 min with the tendon temperature of about $440^{\circ} \mathrm{C}$. The 
variations of tendon stresses in Fig. 11(b) as predicted by the three models show clear correlation with the deflections shown in Fig. 11(a). The tendon stresses predicted by the three models are nearly the same and within the elastic range up to $15 \mathrm{~min}$, but the subsequent plastic deformation of tendon of Eurocode 2 has predicted faster drop of tendon stress as compared to those of the other models. The thermal creep of tendon simulated by the model with creep causes the stress to slowly deviate from that predicted by the model without creep.

Clause 5.2(5) of EN 1992-1-2 [10] specifies the critical temperature for pretressing strands to be $350^{\circ} \mathrm{C}$ for fire-resistance design of prestressed slabs, which accounts for about $82 \mathrm{~min}$ of fire resistance in this FEA. Clause 5.7.2 of EN 1992-1-2 [10] specifies that axis distances to the soffit of simply-supported one-way prestressed slabs of $35 \mathrm{~mm}$ and $45 \mathrm{~mm}$ for fire resistance periods of $60 \mathrm{~min}$ and 90 min respectively. This implies that the axis distance to soffit of $42 \mathrm{~mm}$ in the test slabs should have a design fire resistance period between $60 \mathrm{~min}$ and 90min. Compared with the fire resistance period of 120 min obtained from FEA adopting Eurocode 2 and the model with creep, the estimated fire resistance period based on concrete cover and critical temperature of tendons is quite conservative.

\section{Responses of the slabs in parametric fires}

To investigate the responses of unbonded PT concrete slab in real fire scenarios, two parametric fire curves based on EN 1991-1-2 [12] are adopted. Fig. 12 compares the fire 
scenario curves Fire-1 and Fire-2 against the standard fire (ISO 834). Fire-1 has nearly the same heating rate as the standard fire, but the maximum temperature of about $790^{\circ} \mathrm{C}$ occurs at about $22 \mathrm{~min}$, after which it cools down. Fire-2 has a higher heating rate compared to the standard fire with the maximum temperature of about $1120^{\circ} \mathrm{C}$ reached at about 54 min, after which it cools down. The two fire scenarios account for small fire and severe fire with cooling process, respectively. From the analysis of the verified FE model for T3 under the two parametric fire conditions, the variations of deflection and tendon stress of the two fire scenarios are shown in Figs. 13 and 14, respectively, which show that the maximum deflections always occur during cooling while the minimum tendon stresses occur just after occurrence of the maximum temperature $\left(219^{\circ} \mathrm{C}\right.$ in Fire- 1 and $385^{\circ} \mathrm{C}$ in Fire-2) of the tendon.

Fig.13(a) shows that the slab deflections in scenario Fire-1 predicted by various models are quite consistent, although the deflection predicted by Eurocode 2 becomes slightly higher from about 22min because of plastic deformation of prestressing tendons. The defections predicted by model with and without creep are nearly the same as tendon yielding does not occur and the thermal creep strain calculated from the model with creep has a very small value of $11.7 \times 10^{-6}$ at the end of the 5-hour duration for Fire-1. Fig. 13(b) shows that the tendon stress predicted by Eurocode 2 deviates from those predicted by the other two models at about 22 min and remains lower. The tendon stresses of predicted by models with and without creep are nearly the same because of the relatively low tendon stresses 
compared to the yield strength and the negligible thermal creep strain.

The responses of PT concrete slab in Fig. 14 under scenario Fire-2 indicate obvious discrepancies among deflections and tendon stresses predicted by the three models. In particular, Fig. 14(a) shows that the deflection predicted by Eurocode 2 starts to clearly exceed those predicted by the other two models due to the occurrence of plastic deformation at about 17 min. The deflection predicted by the model with creep gradually exceeds that predicted by the model without creep due to significant accumulation of irrecoverable thermal creep strain with time. Interestingly, the tendon stresses predicted by the three models as shown in Fig. 14(b) are quite different. The stress predicted by the model without creep is the highest among all. The stress predicted by Eurocode 2 is the lowest during the heating process, but it recovers faster than those of the other two models in the cooling process. The stress predicted by the model with creep is the lowest at the end of the 5-hour duration due to irrecoverable thermal creep strain. During cooling, the tendon stresses predicted by the three models start to recover after reaching their respective minimum values, and gradually rising to their final stresses at the end of the 5-hour duration. Therefore, the residual tendon stress is overestimated by the model without creep and possibly by Eurocode 2 for tendon temperature above $385^{\circ} \mathrm{C}$, but the model with creep gives reasonable estimates of residual tendon stresses taking into account irrecoverable thermal creep strains. 


\section{Conclusions}

A nonlinear FE model has been presented for investigating the effects of thermal creep of prestressing steel tendons on unbonded PT concrete slabs in and after fire. The models to predict tendon behaviour include models with and without creep, and that based on Eurocode 2. The FE model was verified against experimental results at ambient condition and in fire conditions with special reference to ultimate loads, tendon strains, cracking modes, temperature field, deflection-time responses and tendon stress-time responses. The FE model has been verified to accurately predict the behaviour of PT concrete slabs at ambient condition and under fire conditions, and the model with creep gives more accurate predictions compared with the other two models under fire conditions.

Effects of thermal creep of prestressing steel tendons on the fire resistance period of PT concrete slabs have been investigated based the verified FE model. The results obtained from FEA indicate that the thermal creep strain of prestressing tendons cannot be ignored; otherwise it will underestimate fire resistance period. The fire resistance periods predicted by the model with creep and Eurocode 2 are nearly the same. Moreover, the fire resistance periods predicted by FEA are all above the design fire resistance period specified in EN 1992-1-2 [10].

The effects of thermal creep of prestressing steel tendons on the responses of PT concrete slabs under post-fire conditions have been investigated based on the verified FE model. The 
results from FEA indicate that the thermal creep strain of prestressing tendons can be ignored only in small fire, but not in severe fire; otherwise it will overestimate the residual tendon stresses and residual load-carrying capacity. The model of Eurocode 2 works well during heating and predicts higher deflections, but may underestimate the residual tendon stresses in small fire conditions and overestimate the residual tendon stress in severe fire conditions after cooling. This may lead to inaccurate evaluation of load-carrying capacity of PT slab under post-fire conditions. The model with creep works well both in small fire conditions and severe fire conditions giving reasonable responses of defection and more accurate residual tendon stresses of PT concrete slabs.

\section{Acknowledgements}

The work described here has been supported by the Research Grants Council (RGC) of Hong Kong Special Administrative Region, China (RGC Project No.: HKU 710012E) and the State Key Laboratory of Subtropical Building Science of South China University of Technology, China (Project No.: 2011KA02). 


\section{References}

[1] Gales J., Bisby L. A., and Gillie M. Unbonded post tensioned concrete in fire: A review of data from furnace tests and real fires. Fire Safety Journal, 2011; 46(4): 151-163.

[2] Gao L. T., Dong Y. L., and Yuan A. M. Experimental investigation of the behaviors of continuous slabs of unbonded prestressed concrete with the end span under fire. Journal of Building Structures, 2004; 25(2): 118-123. (In Chinese)

[3] Yuan A. M., Dong Y. L., Dai H. et al. Experimental investigation of unbonded prestressed concrete continuous slab subjected to fire. Journal of Building Structures, 2006; 27(6): 60-66. (In Chinese)

[4] Zheng W. Z., Hou X. M., et al. Experimental study on concrete spalling in prestressed slabs subjected to fire. Fire Safety Journal, 2010; 45(5): 283-297.

[5] Bailey C. G. and Ellobody E. Fire tests on unbonded post-tensioned one-way concrete slabs. Magazine of Concrete Research, 2009; 61(1), 67-76.

[6] MacLean K. Post-fire Assessment of Unbonded Post-Tensioned Concrete Slabs: Strand Deterioration and Prestress Loss. M.Sc. Thesis, Department of Civil Engineering, Queen’s University, Kingston, ON, Canada, 2007.

[7] Gales J. A. Transient high-temperature prestress relaxation of unbounded Prestressing tendons for use in concrete slabs. M.Sc. Thesis, Department of Civil Engineering, Queen’s University, Kingston, ON, Canada, 2009.

[8] Harmathy T. Z. A comprehensive creep model. National Research Council of Canada, 
Division of Building Research, Ottawa, July 1967.

[9] Gales J. et al. High Temperature Creep Deformation and Failure Behaviour of Prestressing Steel. 7th International Conference on Structures in Fire, SiF'12, June 6, 2012 - June 8, 2012, Zurich, Switzerland.

[10] EN 1992-1-2. Eurocode 2: Design of concrete structures - Part 1-2: General rules Structural fire design, 2004.

[11] Ellobody, E. and C. Bailey. Behaviour of Unbonded Post-Tensioned One-way Concrete Slabs. Advances in Structural Engineering, 2008; 11(1): 107-120.

[12] EN 1991-1-2. Eurocode 1: Actions on structures - Part 1-2: General actions - Actions on structures exposed to fire, 2002.

[13] Kodur V. K. R. and Dwaikat M. M. S. Effect of high temperature creep on the fire response of restrained steel beams. Mater Struct, 2010; 43(10): 1327-1341.

[14] Harmathy T. Z. and Stanzak W. W. Elevated-Temperature Tensile and Creep Properties of Some Structural and Prestressing Steels. National Research Council of Canada, Division of Building Research, Ottawa, January 1970.

[15] Gales J. et al. Transient high-temperature stress relaxation of prestressing tendons in unbonded construction. Fire Safety Journal, 2009; 44(4): 570-579.

[16] EN 1992-1-1. Eurocode 2: Design of concrete structures - Part 1-1: General rules and rules for buildings, 2004.

[17] Bažant, Z. P. Concrete fracture models: testing and practice. Engineering Fracture Mechanics, 2002; 69(2): 165-205. 
[18] Hertz, K. D. Reinforcement data for fire safety design. Magazine of Concrete Research, 2004; 56(8): 453-459.

[19] EN 1993-1-2. Eurocode 3: Design of steel structures - Part 1-2: General rules Structural fire design, 2005.

[20] Ellobody E. A. and Bailey C. G. Modelling of unbonded post-tensioned concrete slabs under fire conditions. Fire Safety Journal, 2009; 44(2): 159-167. 


\section{List of Figure Captions}

Fig. 1 Creep strain at constant stress and temperature: (a) creep strain with time curves; (b) creep strain with temperature-compensated time curve

Fig. 2 Finite element model for a quarter of post-tensioned concrete slab

Fig. 3 Mechanical properties of concrete at ambient conditions: (a) compressive stress-strain relationship; (b) tensile stress-crack displacement relationship

Fig. 4 Mechanical properties of concrete under fire conditions: (a) compressive stress-strain relationship at elevated temperatures; (b) tensile stress-crack displacement relationship at elevated temperatures

Fig. 5 Mechanical properties of prestressing steel under fire conditions: (a) stress-strain relationships from BSEN 1992-1-2; (b) stress-strain relationships based on test and reduction factors in BS EN 1992-1-2

Fig. 6 Comparison of FE and test results: (a) load-deflection curve of T1; (b) load-deflection curve of T2; (c) load-strain curve of prestressing tendon of T2

Fig. 7 Distribution of tensile plastic strains for test T3 based on model with creep

Fig. 8 Transverse stresses in selected elements above central tendon of slab

Fig. 9 Comparison of FE and test results of test T3: (a) temperature field; (b) deflection-time curves

Fig. 10 Comparison of FE and test results of test T5: (a) deflection-time curves; (b) stress-time curves of prestressing tendon

Fig. 11 Reponses of slab T3 under standard fire condition: (a) deflection-time curves; (b) 
stress-time curves

Fig. 12 Fire scenario curves

Fig. 13 Reponses of the slabs in Fire-1: (a) deflection-time curves; (b) stress-time curves

Fig. 14 Reponses of the slabs in Fire-2: (a) deflection-time curves; (b) stress-time curves 


\section{List of Table Captions}

Table 1 Material properties of concrete in tests [5] 


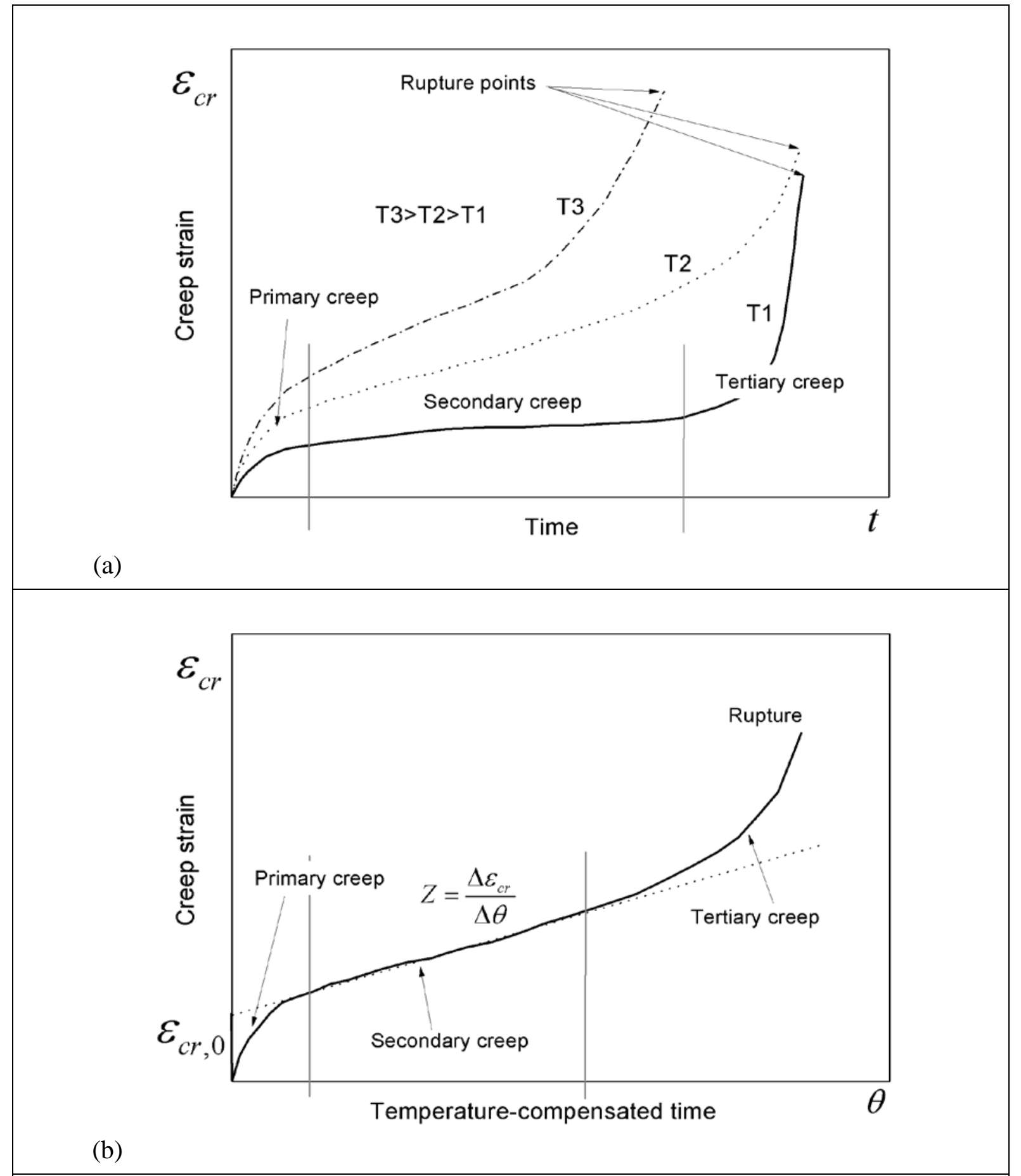

Fig. 1 Creep strain at constant stress and temperature: (a) creep strain with time curves; (b) creep strain with temperature-compensated time curve 


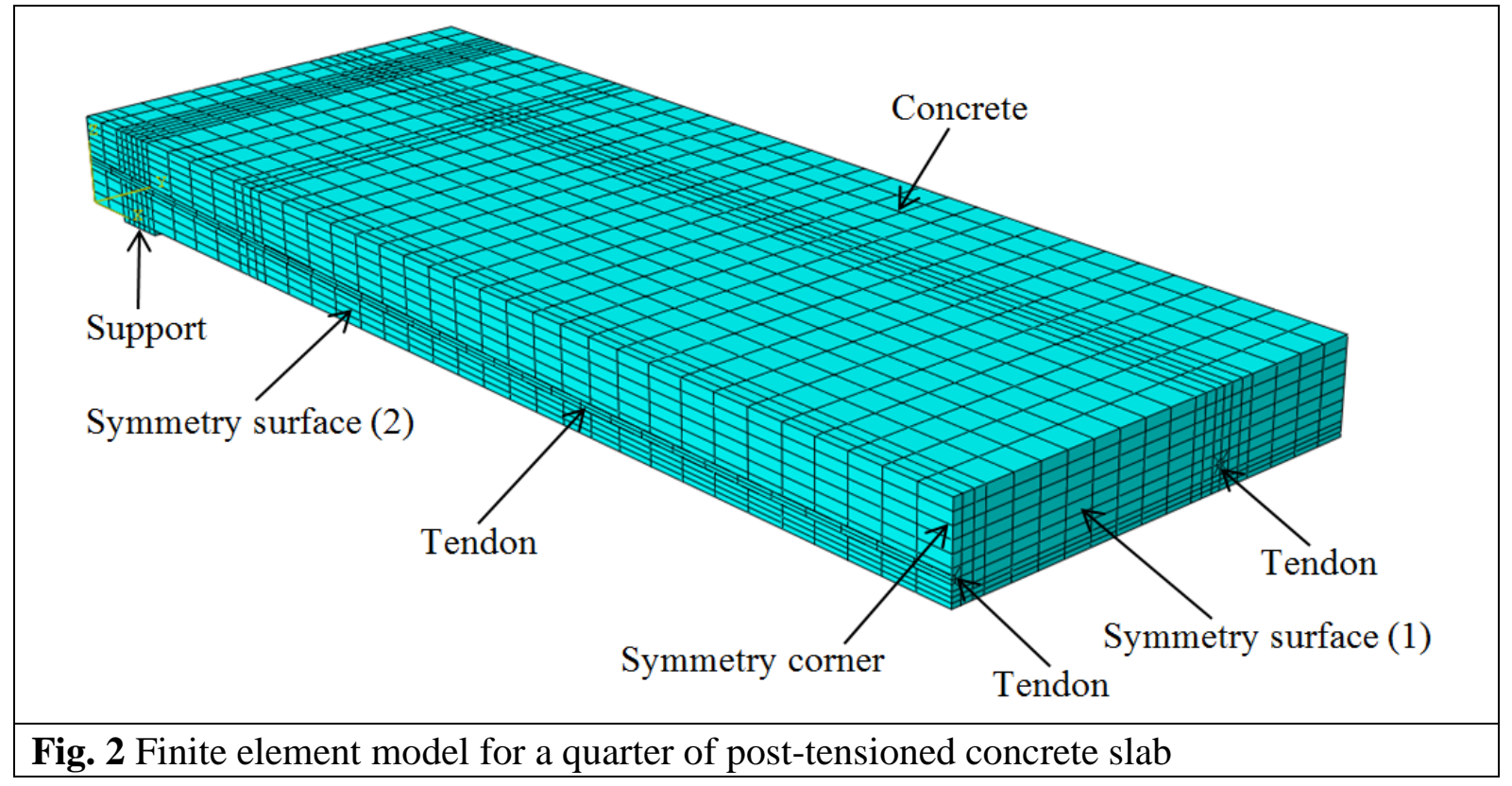




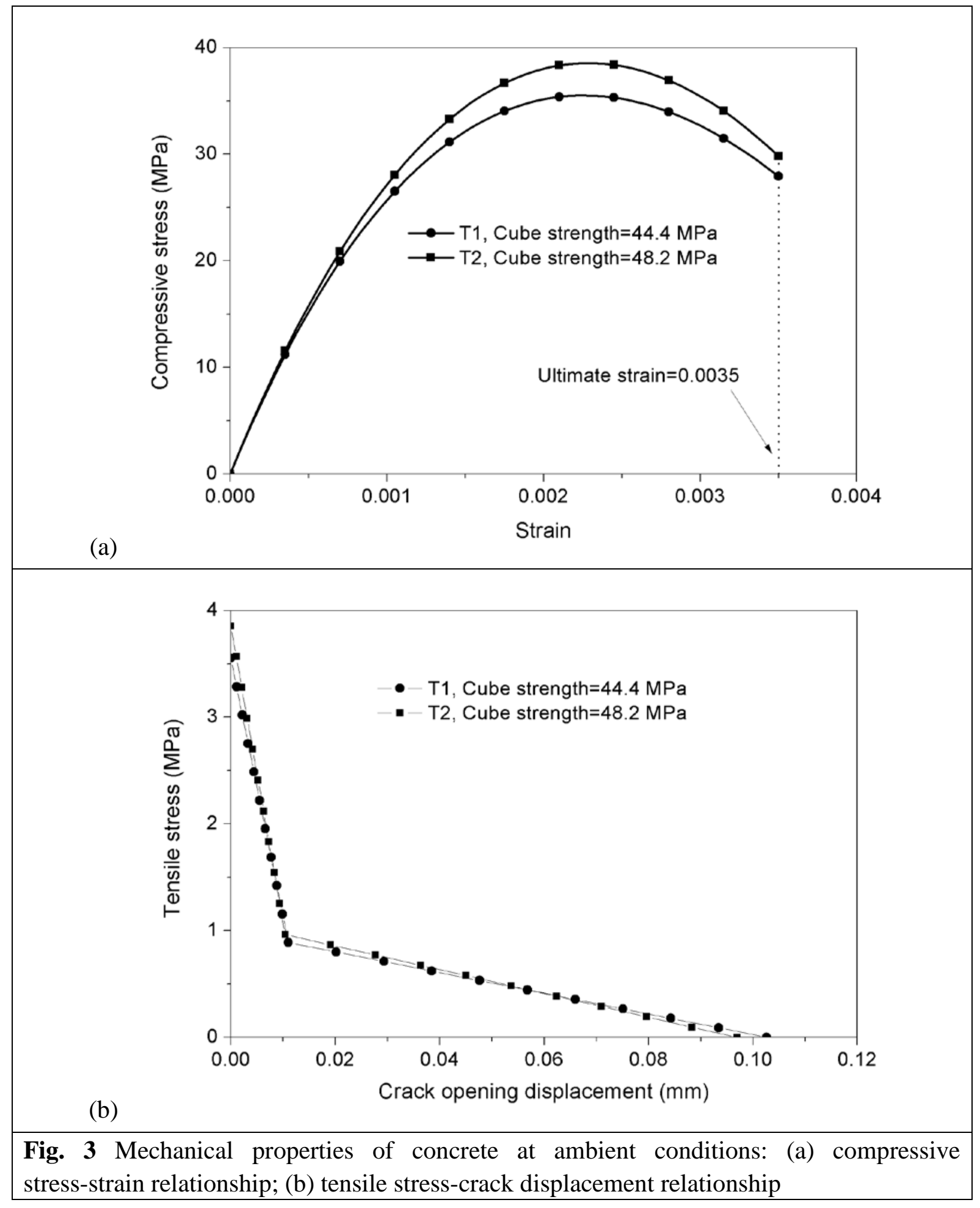




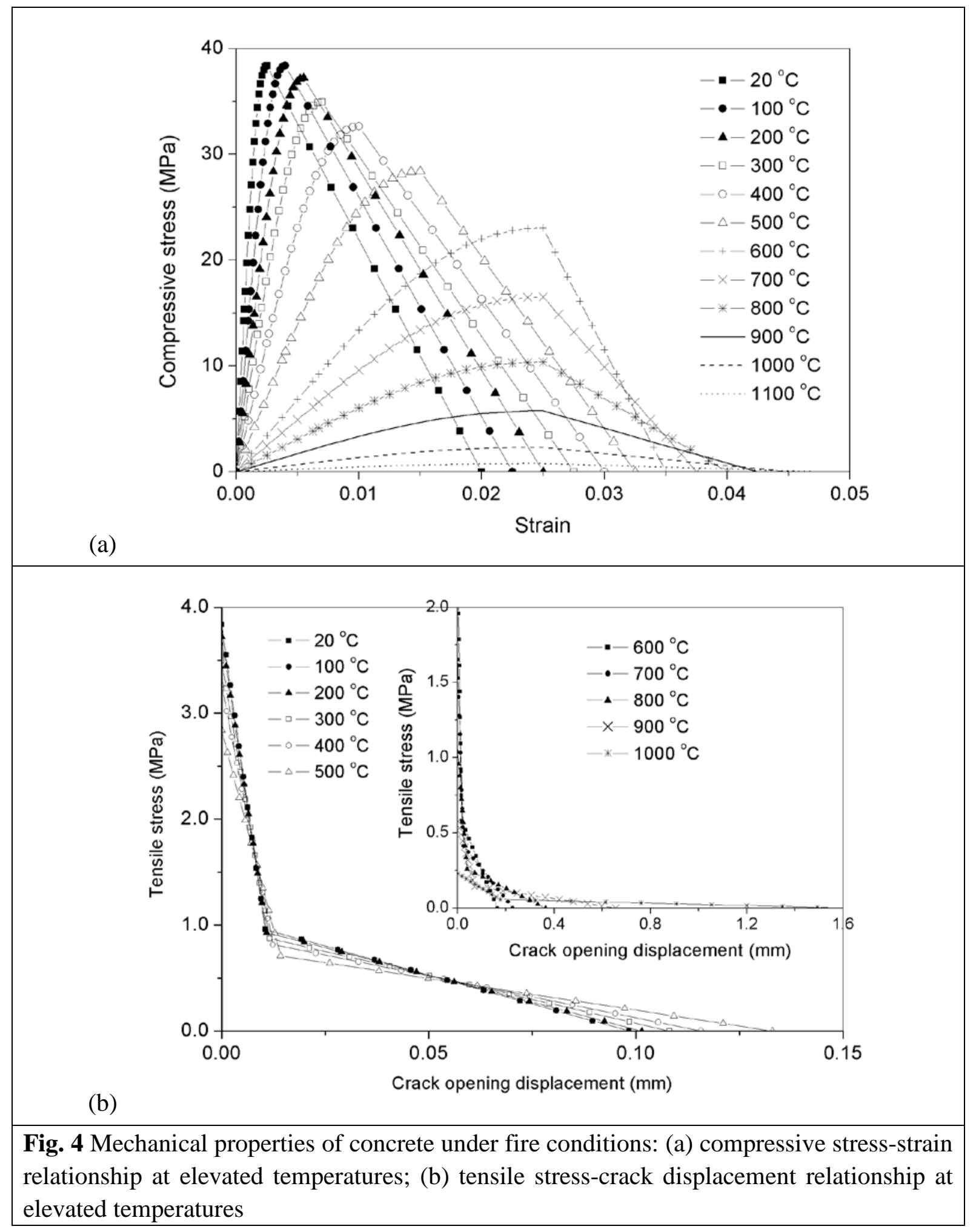




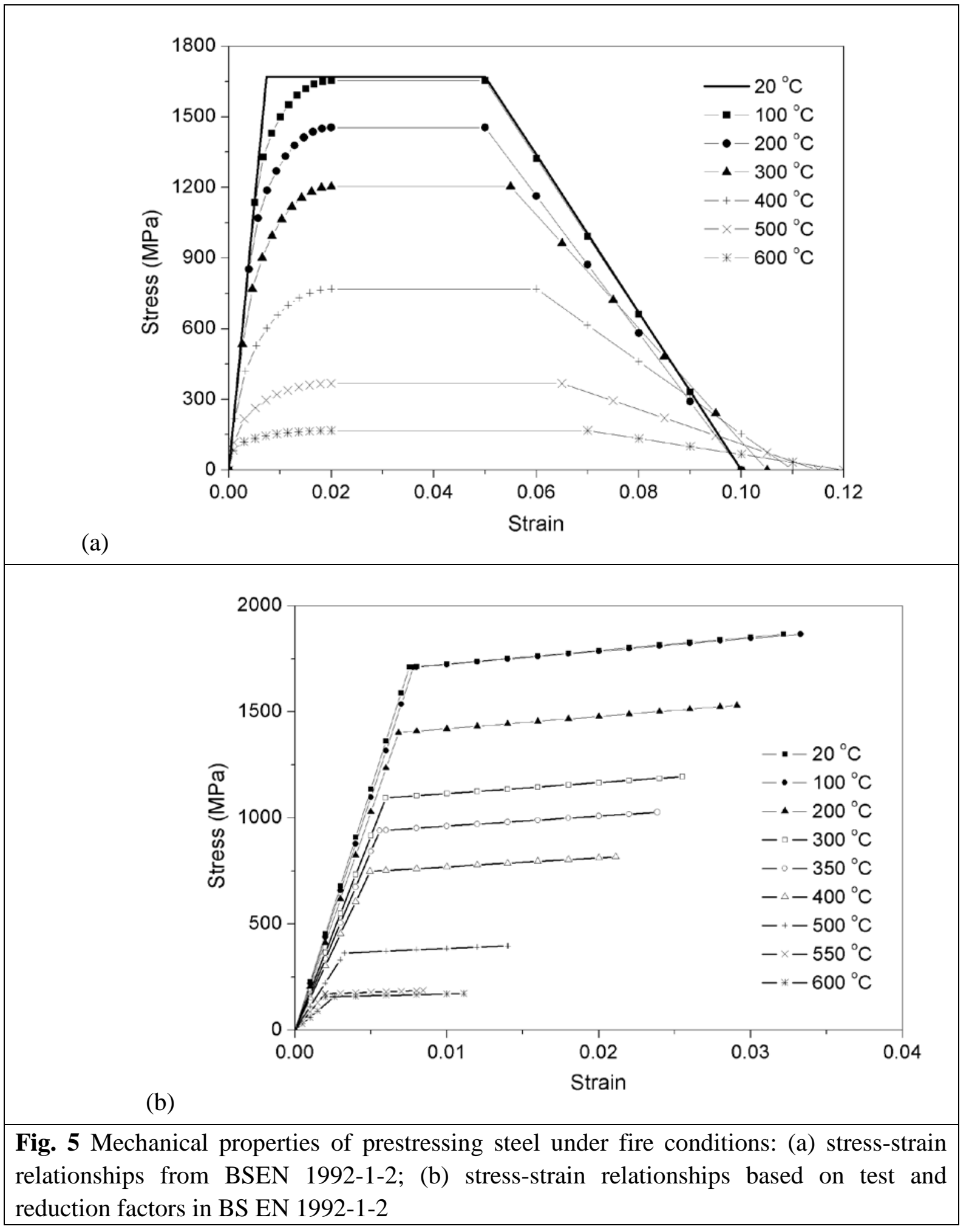




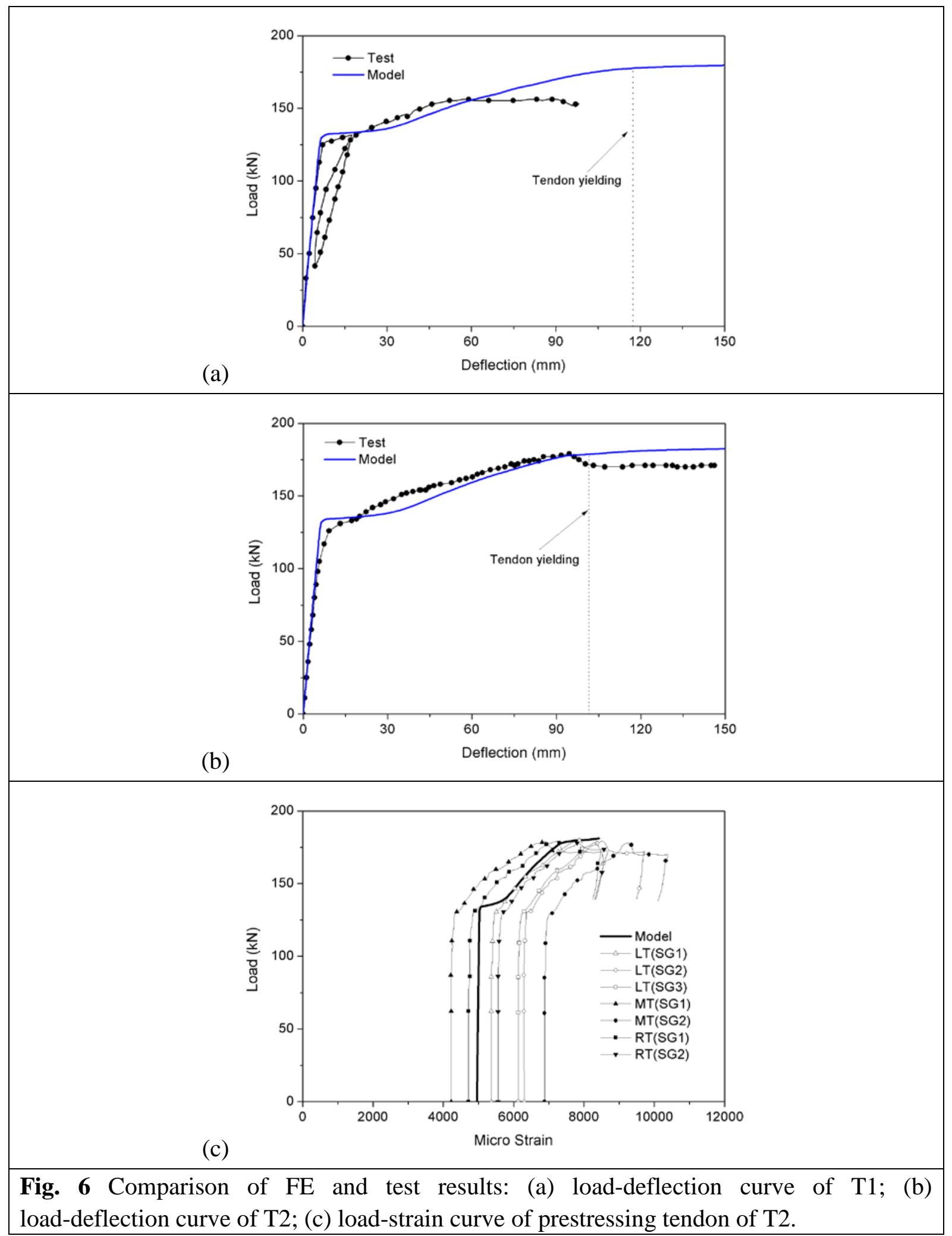




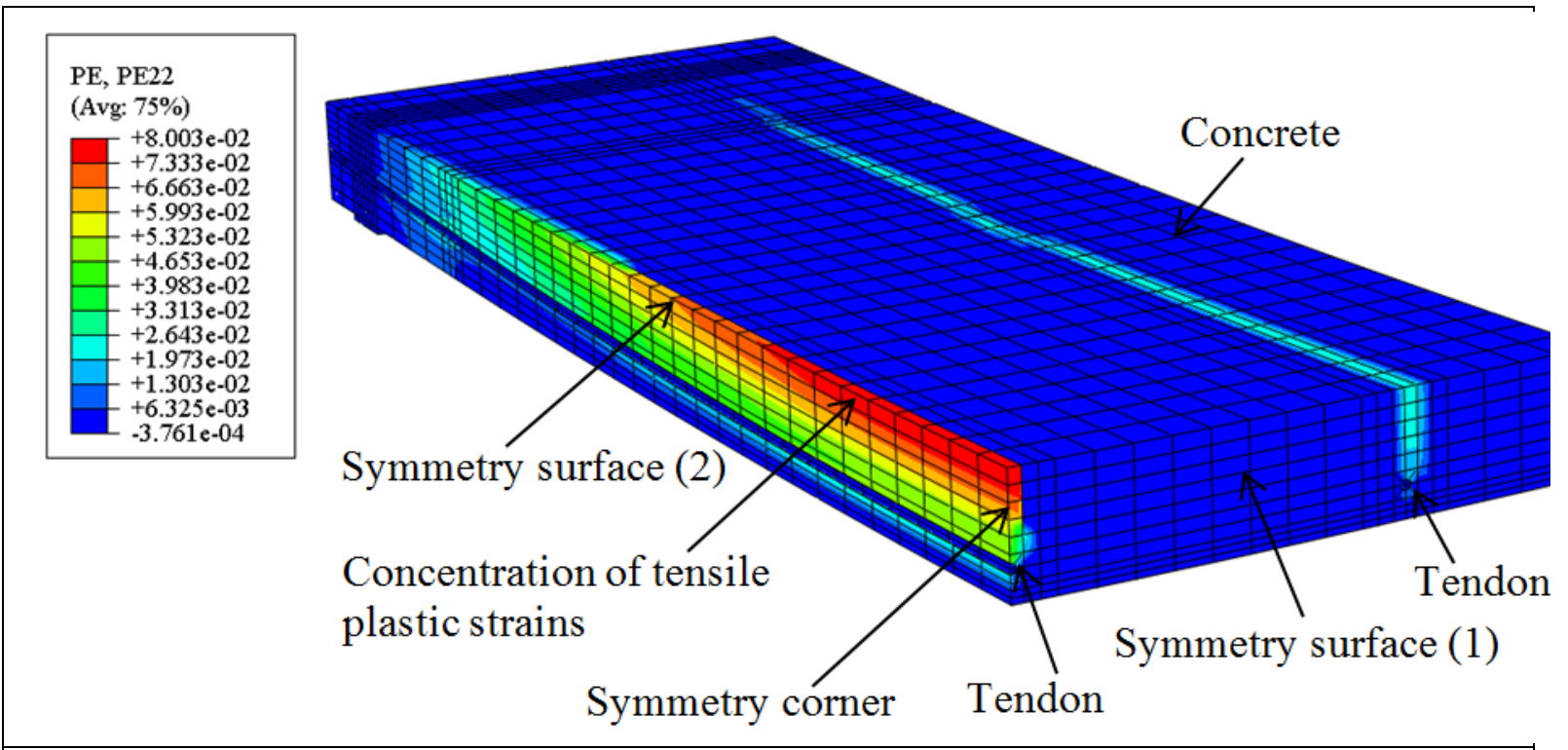

Fig. 7 Distribution of tensile plastic strains for test T3 based on model with creep 


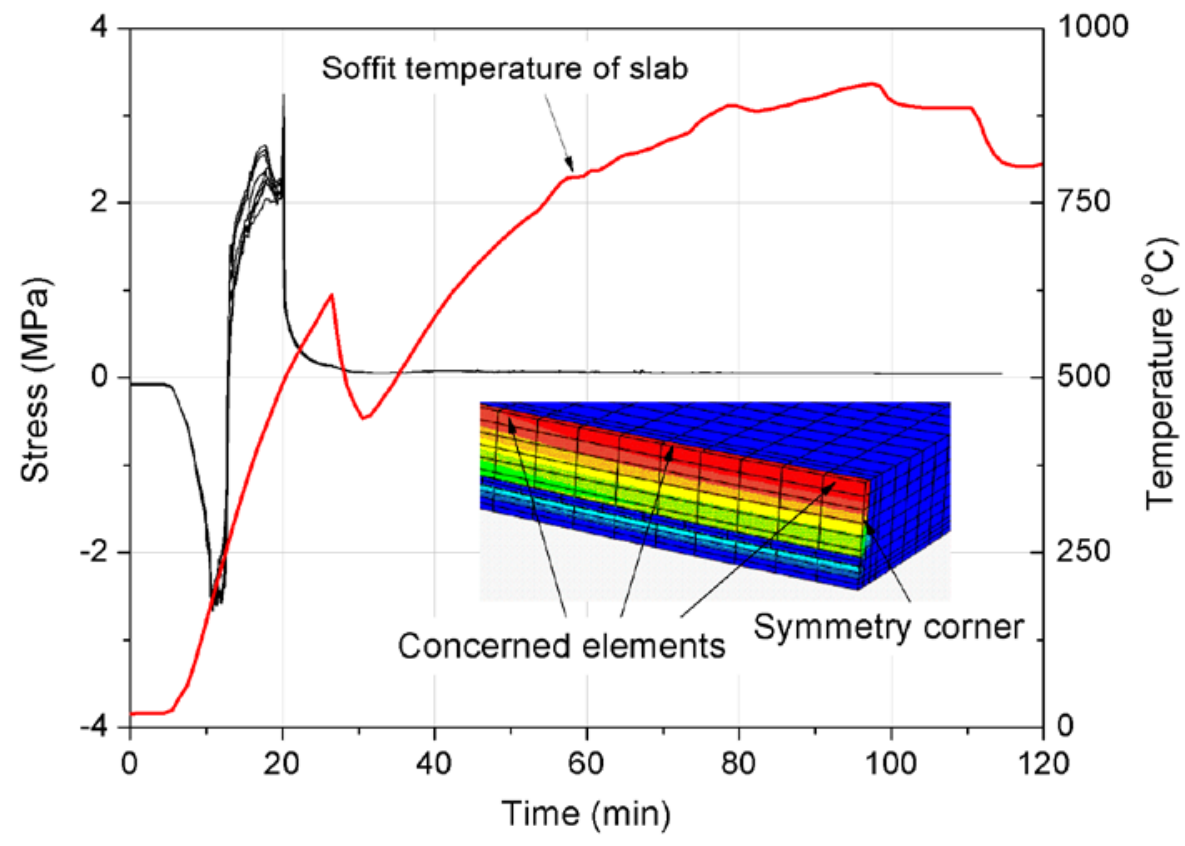

Fig. 8 Transverse stresses in selected elements above central tendon of slab 


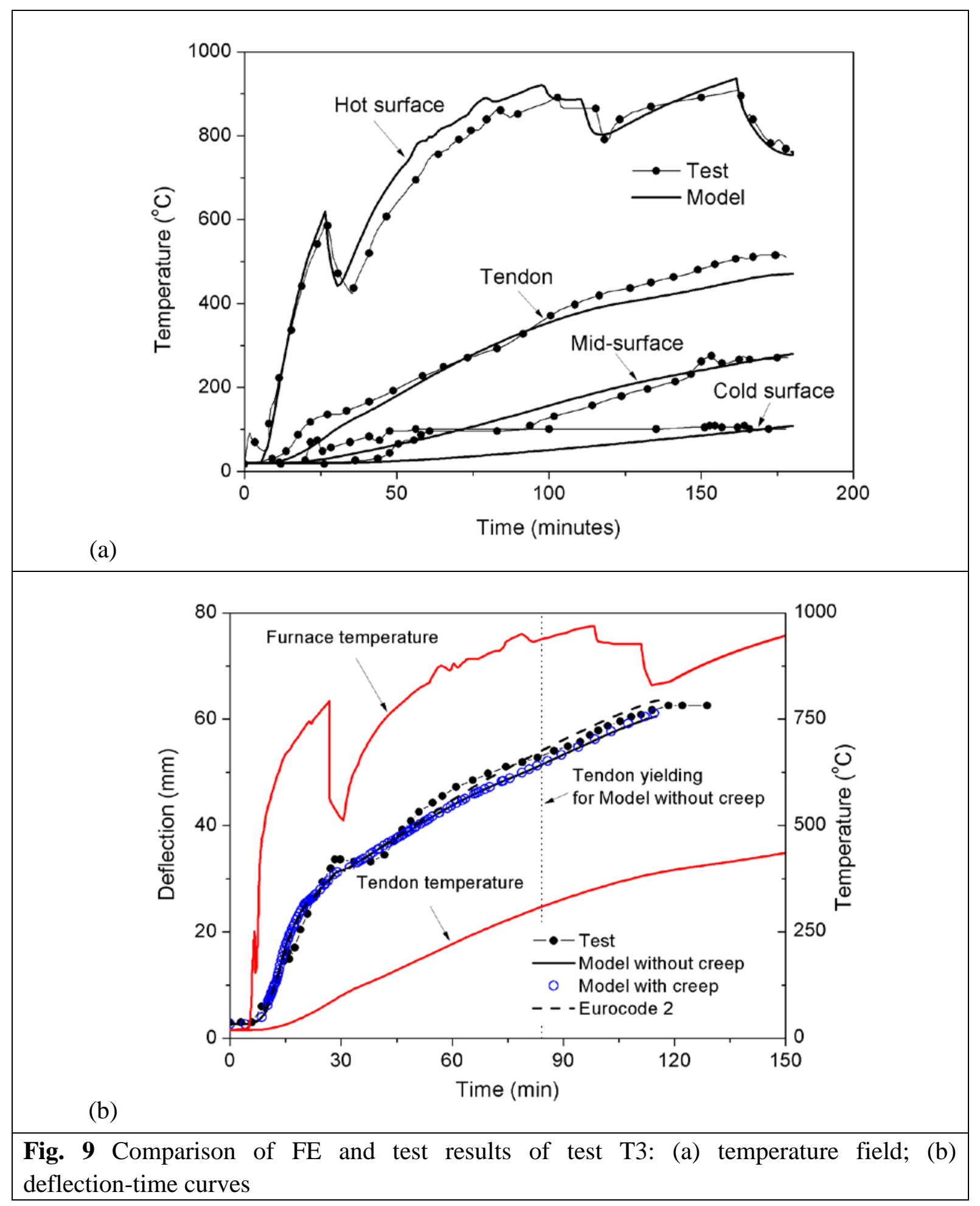




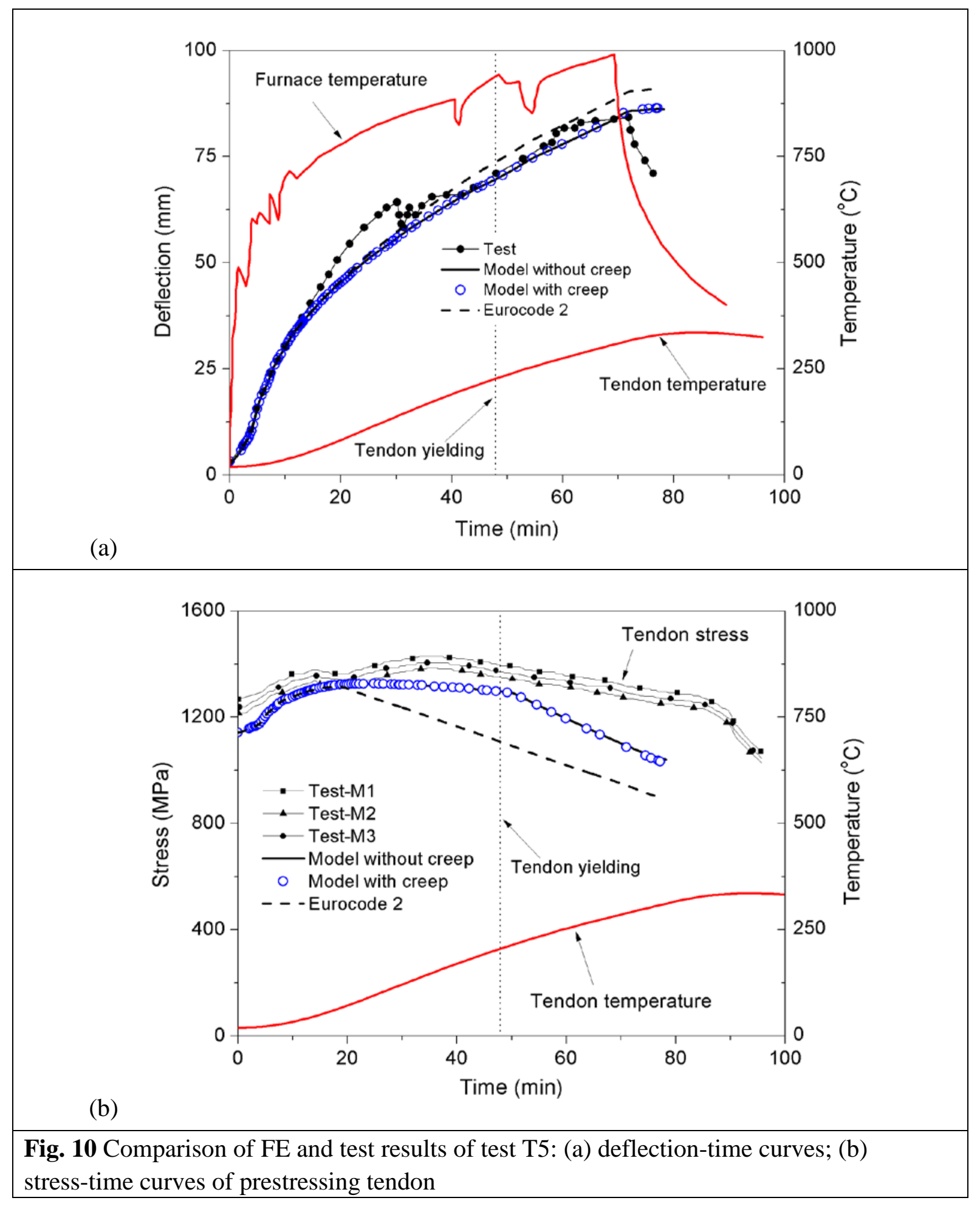




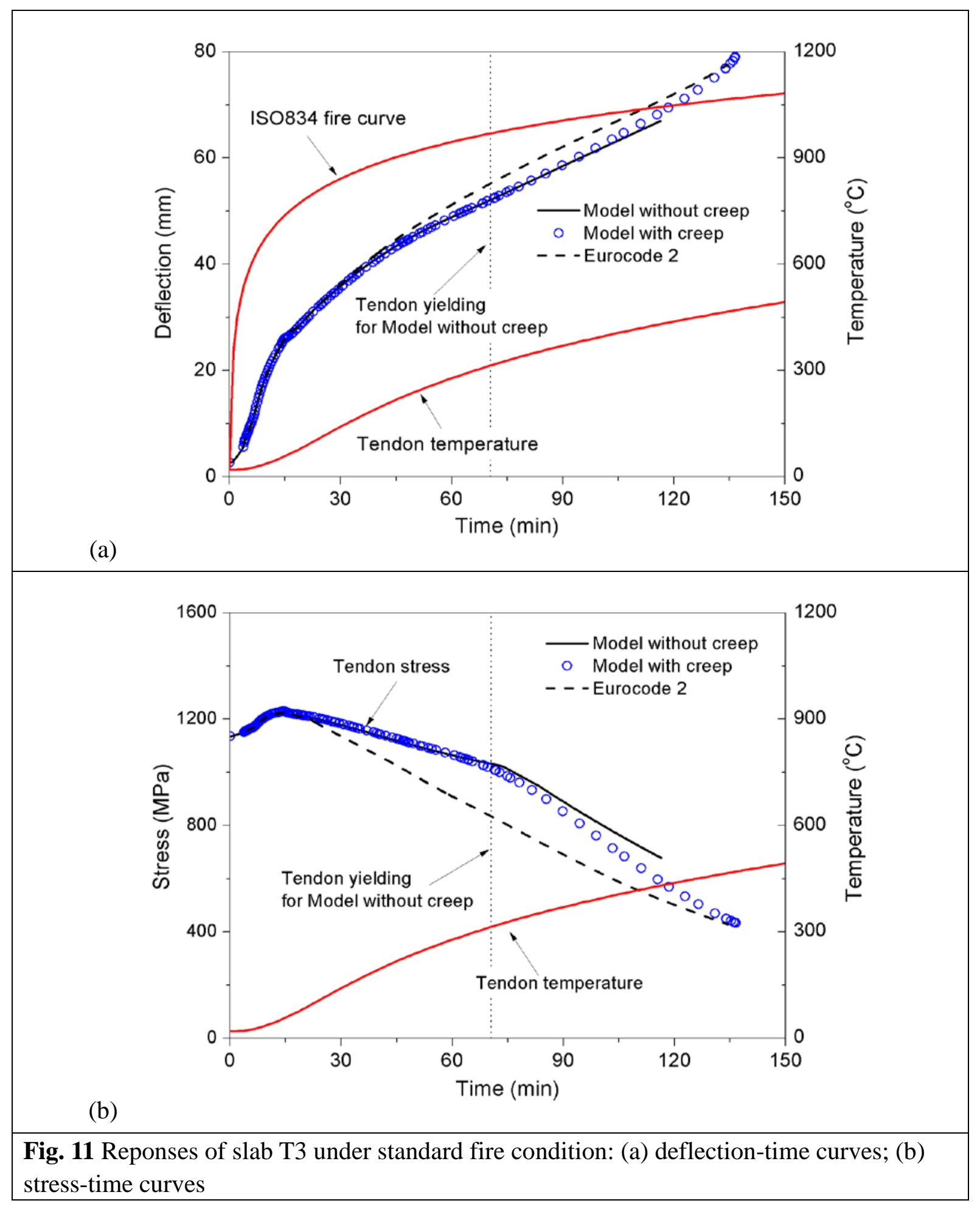




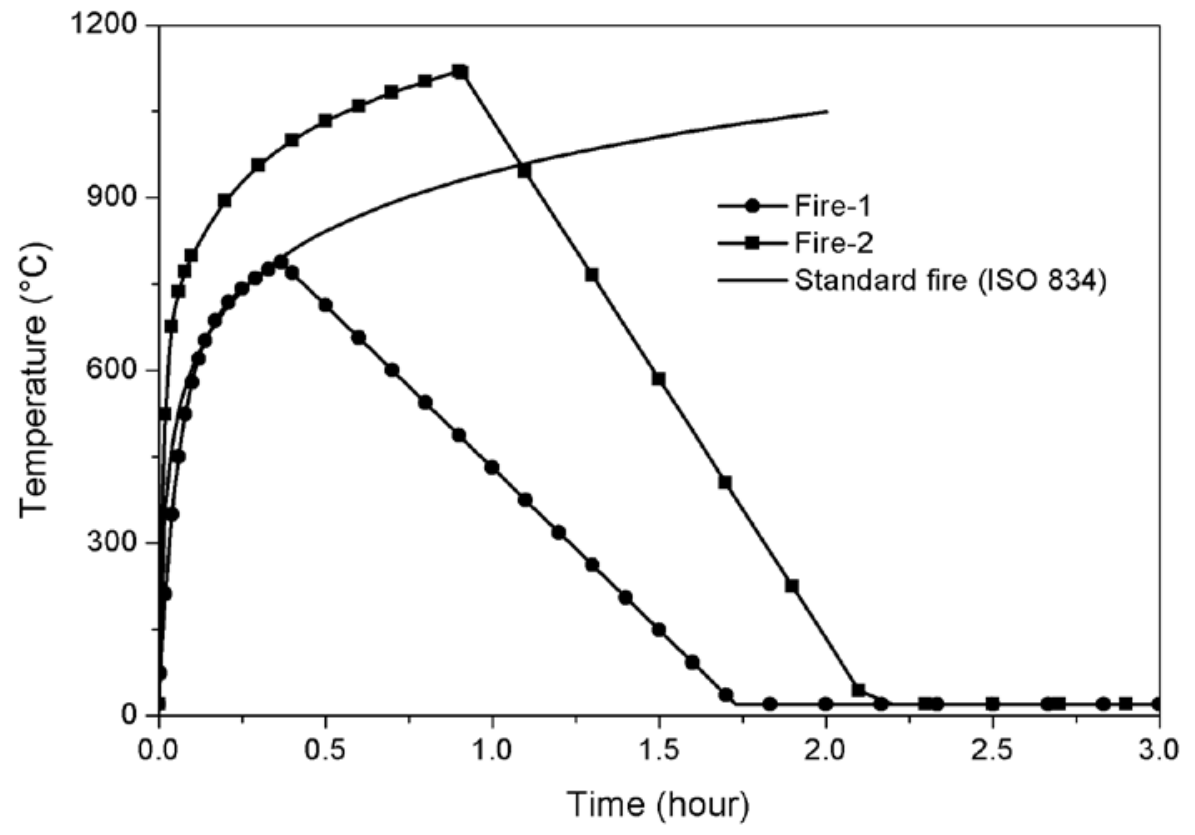

Fig. 12 Fire scenario curves 


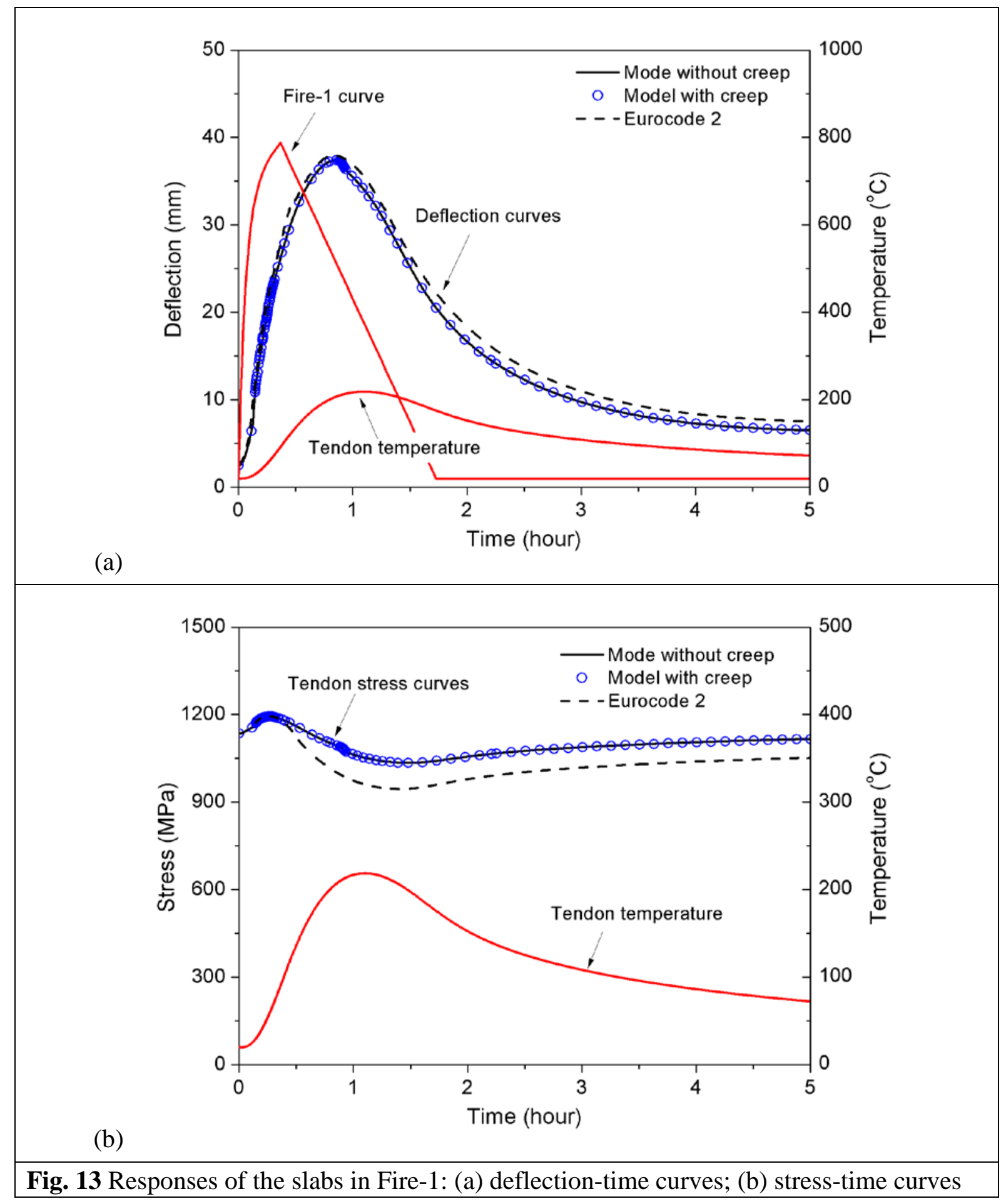




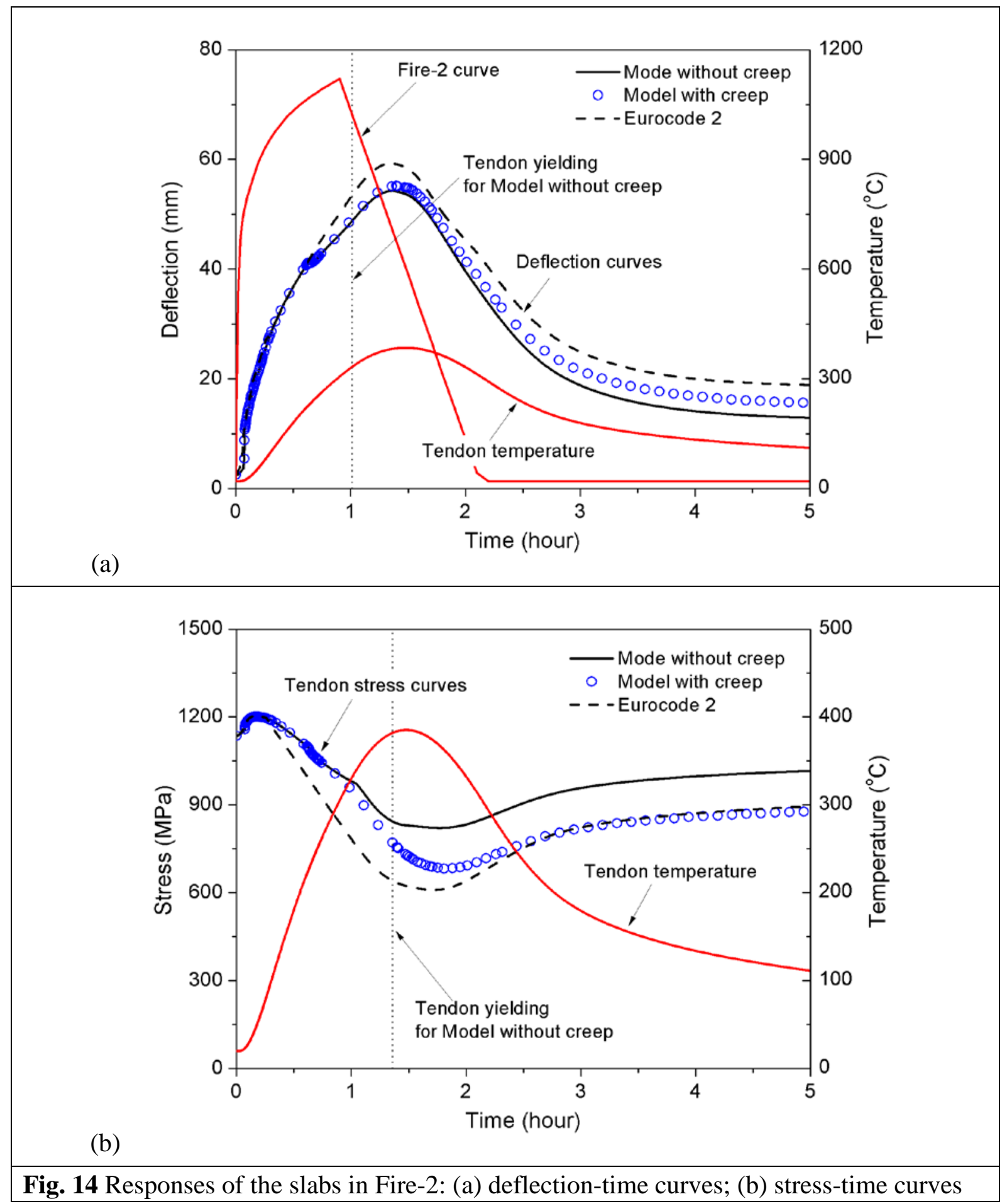


Table 1 Material properties of concrete in tests [5]

\begin{tabular}{ccccc}
\hline Test & $\begin{array}{c}\text { Concrete cube } \\
\text { strength (MPa) }\end{array}$ & Aggregate type & $\begin{array}{c}\text { Moisture } \\
\text { content }(\%)\end{array}$ & $\begin{array}{c}\text { Thermal expansion } \\
\text { coefficient }\end{array}$ \\
\hline T1 & 44.4 & Limestone & - & - \\
T2 & 48.2 & Thames gravel & - & - \\
T3 & 48.0 & Limestone & 2.54 & $8.1 \times 10^{-6}$ \\
T5 & 40.0 & Thames gravel & 2.34 & $13.2 \times 10^{-6}$ \\
\hline
\end{tabular}

